ELSEVIER

RESEARCH LETTER

\title{
Misperception of body weight among overweight or obese adults in Mauritius
}

\section{KEYWORDS}

Weight misperception;

Africa;

Obesity

\section{Introduction}

In the African region, little is known about weight misperception among overweight or obese adults or its correlates $[1,2]$. We assessed the prevalence of weight misperception among overweight or obese individuals in Mauritius. We also examined the association between socio-demographic factors

\begin{abstract}
Summary
Background/objectives: In the African region, little is known about weight misperception among overweight or obese adults. We assessed the prevalence of weight misperception and predictors of weight misperception among overweight or obese adults in Mauritius. Height, weight, and self-perception of weight status data from 5736 adults ( $\geq 19$ years of age), sampled in a population-based survey in 2009 were analysed. Weight status was defined using BMI calculated on the basis of measured height and weight. Information regarding self-perceived body weight, socio-demographic and self-rated health data were collected using a questionnaire. Results: Overall $41 \%$ of overweight or obese adults misclassified their own weight status. Among adults who were overweight or obese, weight misperception was increasingly less likely among those with increasing education (men: $p=0.02$; women: $p \leq 0.001$ ) but was more likely among those who perceived their overall health as good or excellent (men: $P R=1.29,95 \% \mathrm{Cl} 1.10-1.52$; women: $\mathrm{PR}=1.42$, $95 \% \mathrm{Cl} 1.26-1.60)$. Adults who were overweight or obese, weight misperception was increasingly less likely with increasing income (men: $p=0.025$; women: $p \leq 0.001$ ). Among women who were overweight or obese, weight misperception was increasingly more likely with increasing age $(p \leq 0.001)$ and those who self-reported Chinese ethnicity ( $P R=1.48,95 \% \mathrm{Cl} 1.22-1.78)$.

Conclusion: A large proportion of adults in Mauritius misperceive their own weight status, with variation by socio-demographic characteristics and self-rated health. Future studies are needed to examine if correcting misperceptions of weight status may support obesity prevention and control efforts in Mauritius.

(c) 2016 Asia Oceania Association for the Study of Obesity. Published by Elsevier Ltd. All rights reserved.
\end{abstract}


Table 1 Sample characteristics $(n=5736)$ : The Mauritius Non Communicable Diseases Survey 2009.

\begin{tabular}{|c|c|c|c|c|}
\hline Characteristics & All & Men & Women & $p$-Value \\
\hline Age, median (25th-75th percentile), y & $46.0(35.4-56.3)$ & $46.2(36.0-55.9)$ & $45.8(35.0-56.7)$ & 0.929 \\
\hline \multicolumn{5}{|l|}{ Ethnicity $N(\%)$} \\
\hline Indian & $4257(74.2)$ & $2008(74.0)$ & $2249(74.4)$ & \multirow[t]{3}{*}{0.130} \\
\hline Afro-Malagasy & $1317(23.0)$ & $618(22.8)$ & $699(23.1)$ & \\
\hline Chinese & $162(2.8)$ & $88(3.2)$ & $74(2.4)$ & \\
\hline \multicolumn{5}{|l|}{ Education, $N(\%)$} \\
\hline None or $1-3 y$ & $561(9.8)$ & $148(5.5)$ & $413(13.7)$ & \multirow[t]{5}{*}{$<0.001$} \\
\hline $4-6 y$ & $2090(36.4)$ & $904(33.3)$ & $1186(39.3)$ & \\
\hline $7-9 y$ & 607 (10.6) & $315(11.6)$ & $292(9.7)$ & \\
\hline $10-12 y$ & 1977 (34.5) & $1036(38.2)$ & $941(31.0)$ & \\
\hline Tertiary & $501(8.7)$ & $311(11.5)$ & $190(6.3)$ & \\
\hline \multicolumn{5}{|l|}{ Monthly family income ${ }^{a}, N(\%)$} \\
\hline$<5000$ & $1148(20.1)$ & $296(10.9)$ & $852(28.3)$ & \multirow[t]{4}{*}{$<0.001$} \\
\hline 5000 to $<10,000$ & $2015(35.1)$ & $972(35.8)$ & $1043(34.6)$ & \\
\hline 10,000 to $<15,000$ & $1088(19.0)$ & $572(21.1)$ & $516(17.0)$ & \\
\hline$\geq 15,000$ & 1485 (25.9) & $874(32.2)$ & $611(20.1)$ & \\
\hline \multicolumn{5}{|l|}{ Perception of overall health } \\
\hline Poor or average & 2057 (35.9) & $847(31.2)$ & $1210(40.0)$ & \multirow[t]{2}{*}{$<0.001$} \\
\hline Good or excellent & $3679(64.1)$ & $1867(68.8)$ & $1867(68.8)_{-}$ & \\
\hline \multicolumn{5}{|l|}{ BMI classification $N(\%)$} \\
\hline Underweight & $296(5.2)$ & $148(5.5)$ & $148(4.9)$ & \multirow[t]{4}{*}{$<0.001$} \\
\hline Normal weight & $2532(44.1)$ & $1335(49.2)$ & $1197(39.6)$ & \\
\hline Overweight & $1981(34.5)$ & $932(34.3)$ & $1049(34.7)$ & \\
\hline Obese & $927(16.2)$ & $299(11.0)$ & $628(20.8)$ & \\
\hline
\end{tabular}

Survey. The study was approved by the local ethics committee.

BMI was calculated from measured weight $(\mathrm{kg})$ divided by the height squared (metres). Overweight was defined as BMI $25-29.9 \mathrm{~kg} / \mathrm{m}^{2}$ and obesity as $B M I \geq 30 \mathrm{~kg} / \mathrm{m}^{2}$. Perceived healthy weight was assessed through the following question: "Do you think your current weight is?" Participants provided one of the following responses, "Too low", "About right", "A little too high", or "Much too high". Misperception of weight status among overweight and obese adults was defined by discordance between the actual weight category and the perceived weight as evidenced by answering "Too low", or "About right" to the question on weight status perception.

The Kappa coefficient with $95 \%$ confidence intervals $(\mathrm{Cl})$ was calculated to measure agreement between perceived body weight status and measured weight status. The association of socio-demographic characteristics (age, ethnicity, education level, and monthly family income), and self-rated heath to weight misperception prevalence among overweight or obese adults was examined in a multivariable Poisson regression model to estimate adjusted prevalence ratios (PRs) and $95 \% \mathrm{Cl}$.

\section{Results}

Of the 6318 participants aged $20-74$ years, who were non-pregnant and had complete data on ethnicity, we excluded those with missing information on age $(n=36)$, education level $(n=64)$, income level $(n=281)$, self-rated health $(n=19)$, weight perception $(n=131)$ and $\mathrm{BMI}(n=51)$. Our analytic sample was 5736 participants $(90.8 \%$ of the eligible sample).

On the basis of calculated BMI, $50.7 \%$ of the total participants were overweight or obese (Table 1). The overall percentage of agreement among those who judged their own weight status correctly was $67.2 \%$. In both sexes, the Kappa coefficient indicated weak agreement $(0.40-0.41)$ between perceived weight status and actual BMI. Overall, $40.8 \%$ of overweight or obese adults misclassified their own weight status (men: $45.3 \%$ vs. women: $37.5 \% ; p=0.0001$ ). Among adults who were overweight or obese, weight misperception was increasingly less likely among those with increasing education (men: $p=0.02$; women: $p \leq 0.001$ ) but was more likely among those who perceived their overall health as good or excellent (men: $P R=1.29$, $95 \% \mathrm{Cl} 1.10-1.52$; women: $P R=1.42,95 \% \mathrm{Cl}$ 1.26-1.60). Adults who were overweight or obese, 
Table 2 Correlates of misperceived weight status among overweight or obese Mauritian adults: Mauritius Non Communicable Diseases Survey 2009.

\begin{tabular}{|c|c|c|}
\hline \multirow[t]{2}{*}{ Characteristic } & \multicolumn{2}{|c|}{ Adjusted prevalence ratio $(95 \% \mathrm{Cl})$} \\
\hline & Men & Women \\
\hline \multicolumn{3}{|l|}{ Age group, years } \\
\hline $19-39$ & 1 [reference] & 1 [reference] \\
\hline $40-59$ & $1.10(0.92-1.31)$ & $1.44(1.23-1.69)$ \\
\hline $60-79$ & $1.18(0.95-1.46)$ & $1.89(1.59-2.23)$ \\
\hline$p$ for trend & 0.086 & $<0.001$ \\
\hline \multicolumn{3}{|l|}{ Ethnicity } \\
\hline South Asian & 1 [reference] & 1 [reference] \\
\hline Afro-Malagasy & $0.97(0.85-1.10)$ & $0.97(0.85-1.1)$ \\
\hline Chinese & $1.27(0.93-1.72)$ & $1.45(1.27-1.65)$ \\
\hline \multicolumn{3}{|l|}{ Education } \\
\hline None or $1-3 y$ & 1 [reference] & 1 [reference] \\
\hline $4-6 y$ & $0.95(0.73-1.22)$ & $0.96(0.79-1.16)$ \\
\hline $7-9 y$ & $0.79(0.61-1.01)$ & $0.68(0.51-0.91)$ \\
\hline $10-12 y$ & $0.80(0.58-1.10)$ & $0.53(0.38-0.75)$ \\
\hline Tertiary & $0.72(0.52-0.99)$ & $0.24(0.09-0.67)$ \\
\hline$p$ for trend & 0.021 & $<0.001$ \\
\hline \multicolumn{3}{|c|}{ Monthly family income (rupees) } \\
\hline$<5000$ & 1 [reference] & 1 [reference] \\
\hline $5000<10,000$ & $0.90(0.75-1.09)$ & $0.93(0.81-1.06)$ \\
\hline $10,000<15,000$ & $0.88(0.70-1.10)$ & $0.73(0.58-0.92)$ \\
\hline$\geq 15,000$ & $0.73(0.55-0.97)$ & $0.65(0.51-0.83)$ \\
\hline$p$ for trend & 0.025 & $<0.001$ \\
\hline \multicolumn{3}{|c|}{ Perception of overall health } \\
\hline Average or poor & 1 [reference] & 1 [reference] \\
\hline Good or excellent & $1.34(1.16-1.57)$ & $1.48(1.30-1.69)$ \\
\hline
\end{tabular}

weight misperception was increasingly less likely with increasing income (men: $p=0.025$; women: $p \leq 0.001$ ). Among women who were overweight or obese, weight misperception was increasingly more likely with increasing age $(p \leq 0.001)$ and those who self-reported Chinese ethnicity $(P R=1.48,95 \% \mathrm{Cl}$ 1.22-1.78).

\section{Discussion}

The high prevalence of weight misperception among overweight or obese Mauritian adults may reflect the increases in obesity prevalence during the past 22 years [3], where socially accepted "normal" weight may have also shifted accordingly. Women who were overweight or obese tended to misperceive their weight status less than men, similar to findings that suggest that women are more aware of their weight status than men $[4,5]$. Socio-cultural pressures to maintain a thin body weight are reported to affect women more than men [6] and therefore may be more sensitive of their weight and perceive their weight more accurately. Weight misperception is also known to increase with age in high-income countries [7], and might suggest the tendency of older adults to consider weight gain as a normal aspect of ageing [8]. We found that Chinese women who were overweight or obese were more likely to misperceive their weight status compared to Indian women. Historically, Chinese societies have discouraged a preoccupation with physical appearance and thinness [9]. Western concepts and ideals of thinness could have been less fully internalised among Chinese women in Mauritius. We also found among overweight and obese adults, weight misperception was less prevalent for those with higher socioeconomic status. This may be because they have better access to health related information that raises awareness of their BMI [10]. Both men and women who were overweight or obese and who rated their overall health as good or excellent were more likely to misperceive their weight status. An explanation for this might be that adults who feel healthy and have no apparent disease or physical health limitations, may not believe that public health messages about excess weight apply to them (Table 2).

Our study has limitations. The cross sectional study design limited our ability to confirm the direction of any association between the identified correlates and weight misperception. Also, we were only able to assess body weight perception, which is a component of body image. 


\section{Conclusion}

Further research is needed to investigate if correcting weight misperceptions may be a useful strategy to support adult obesity prevention and control in Mauritius.

\section{Conflicts of interest}

None.

\section{Acknowledgements}

We are most grateful to the participants for volunteering their valuable time, the work of the staff at the Ministry of Health and Quality of Life in Mauritius and the many people involved in organising and conducting the 2009 Mauritius National Non Communicable Diseases Survey.

\section{References}

[1] Ettarh R, Van de Vijver S, Oti S, Kyobutungi C. Overweight, obesity, and perception of body image among slum residents in Nairobi, Kenya, 2008-2009. Prevent Chronic Dis 2013;10:E212.

[2] McHiza ZJ, Parker WA, Makoae M, Sewpaul R, Kupamupindi $\mathrm{T}$, Labadarios D. Body image and weight control in South Africans 15 years or older: SANHANES-1. BMC Public Health 2015;15:992.

[3] Magliano DJ, Söderberg S, Zimmet PZ, Chen L, Joonas N, Kowlessur S, et al. Explaining the increase of diabetes prevalence and plasma glucose in Mauritius. Diabetes Care 2012;35(1):87-91, http://dx.doi.org/10.2337/dc11-0886.

[4] Matthiessen J, Biltoft-Jensen A, Fagt S, Knudsen VK, Tetens I, Groth MV. Misperception of body weight among overweight Danish adults: trends from 1995 to 2008. Public Health Nutr 2014;17(7):1439-46, http://dx.doi.org/ 10.017/S1368980013001444.

[5] Yaemsiri S, Slining MM, Agarwal SK. Perceived weight status, overweight diagnosis, and weight control among US adults: the NHANES 2003-2008 Study. Int J Obes (Lond) 2011;35(8):1063-70, http://dx.doi.org/10.38/ ijo.2010.229.

[6] Swami V, Frederick DA, Aavik T, Alcalay L, Allik J, Anderson $D$, et al. The attractive female body weight and female body dissatisfaction in 26 countries across 10 world regions: results of the international body project I. Pers Soc Psychol Bull 2010;36(3):309-25.

[7] Salcedo V, Gutierrez-Fisac JL, Guallar-Castillon P, Rodriguez-Artalejo F. Trends in overweight and misperceived overweight in Spain from 1987 to 2007. Int J Obes (Lond) 2010;34(12):1759-65, http://dx.doi.org/10.038/ ijo.2010.96.
[8] Brug J, Wammes B, Kremers S, Giskes K, Oenema A. Underestimation and overestimation of personal weight status: associations with socio-demographic characteristics and weight maintenance intentions. J Hum Nutr Diet 2006;19(4):253-62.

[9] Luo Y, Parish WL, Laumann EO. A population-based study of body image concerns among urban Chinese adults. Body Image 2005;2(4):333-45.

[10] Bhanji S, Khuwaja AK, Siddiqui F, Azam I, Kazmi K. Underestimation of weight and its associated factors among overweight and obese adults in Pakistan: a cross sectional study. BMC Public Health 2011;11:363.

Rishi Caleyachetty ${ }^{\mathrm{a}, \mathrm{b}, *}$

${ }^{a}$ Ministry of Health and Quality of Life, Port Louis, Mauritius

${ }^{\mathrm{b}}$ MRC Unit for Lifelong Health and Ageing at University College London, UK

Andre P. Kengne $\mathrm{a}^{\mathrm{a}, \mathrm{b}, \mathrm{c}}$

a South African Medical Research Council and University of Cape Town, Cape Town, South Africa

${ }^{\mathrm{b}}$ The George Institute for Global Health, Sydney, Australia

c Julius Center for Health Sciences and Primary Care, University Medical Centre, Utrecht, The Netherlands

Peter Muennig Department of Health Policy and Management, Mailman School of Public Health, Columbia University, NY 10032, USA

Harry Rutter European Centre on Health of Societies in Transition, Department of Health Services Research and Policy, London School of Hygiene and Tropical Medicine, London, UK

Justin B. Echouffo-Tcheugui ${ }^{\mathrm{a}, \mathrm{b}}$ a Hubert Department of Global Health, Rollins School of Public Health, Emory University, Atlanta, GA, USA

${ }^{\mathrm{b}}$ Department of Medicine, MedStar Health, Baltimore, MD, USA

* Corresponding author at: MRC Unit for Lifelong Health and Ageing at University College London, 33 Bedford Place, London WC1B 5JU, UK. Tel.: +44 02077726490; fax: +4402077230575. E-mail address: r.caleyachetty@icloud.com (R. Caleyachetty) 1 February 2016

Available online at www.sciencedirect.com

\section{ScienceDirect}

